\title{
Prognostic factors of second primary contralateral breast cancer in early-stage breast cancer
}

\author{
ZHENG LI $^{1}$, FABRICE SERGENT ${ }^{2}$, MICHEL BOLLA $^{3}$, YUNFENG ZHOU $^{1}$ and ISABELLE GABELLE-FLANDIN ${ }^{3}$ \\ ${ }^{1}$ Department of Radiation and Medical Oncology, Zhongnan Hospital Affiliated to Wuhan University, \\ Wuhan, Hubei 430071, P.R. China; Departments of ${ }^{2}$ Gynecology and ${ }^{3}$ Radiation Oncology, \\ Central Hospital of Grenoble University, Grenoble 38043, France
}

Received November 25, 2013; Accepted July 8, 2014

DOI: $10.3892 / \mathrm{ol} .2014 .2623$

\begin{abstract}
The aim of the present study was to investigate the therapeutic outcome of early-stage breast cancer (pT1aN0M0) and to identify prognostic factors for secondary primary contralateral breast cancer $(\mathrm{CBC})$. A total of 85 patients with mammary carcinomas were included. All patients had undergone breast surgery and adjuvant treatment between January 2001 and December 2008 at the Central Hospital of Grenoble University (Grenoble, France). The primary end-points were disease-free survival and secondary CBC, and the potential prognostic factors were investigated. During a median follow-up of 60 months, 10 of the 85 patients presented with secondary primary cancer, of which six suffered with $C B C$. No patient mortalities were reported. The rates of $\mathrm{CBC}$ were $2.35,3.53$ and $7.06 \%$ at one, two and five years, respectively. The cumulative univariate analysis showed that microinvasion and family history are potential risk factors for newly $\mathrm{CBC}$. The current study also demonstrated that secondary CBC was more likely to occur in patients with microinvasion or a family history of hte dise. In addition, the systematic treatment of secondary CBC should include hormone therapy.
\end{abstract}

\section{Introduction}

Breast cancer is the most common type of cancer in females in developed and developing countries. Since 2004, a French national screening program of breast cancer has been established for females between 50-74 years old (1). Mass

Correspondence to: Dr Isabelle Gabelle-Flandin, Department of Radiation Oncology, Central Hospital of Grenoble University, Boulevard de la Chantourne, Grenoble 38043, France

E-mail: IgabelleFlandin@chu-grenoble.fr

Dr Yunfeng Zhou, Department of Radiation and Medical Oncology, Zhongnan Hospital Affiliated to Wuhan University, 169 Donghu Road, Wuhan, Hubei 430071, P.R. China

E-mail: yfzhou_whu@163.com

Key words: breast cancer, radiotherapy, contralateral breast cancer, risk factors screening for breast cancer has led to the identification of 14,500 novel breast cancers, with a rate of 6.7 cancers identified per 1,000 females screened. In 2011, breast cancer was the most common type of cancer among French females, with 53,000 new cases identified, followed by colorectal cancer $(19,000$ cases $)$ and lung cancer $(12,000$ cases $)$. In addition, breast cancer continued to be the leading cause of cancer-related mortality, with 11,500 mortalities, in 2011. However, the rate of breast cancer-related mortality has actually decreased since 1946 (2).

Various studies have identified a number of risk factors, including age, lymphovascular emboli or invasion (LVI), menopause, hormone receptors and the type of treatments, which may affect the survival of early-stage breast cancer patients (3-11).

Few studies has described early breast cancer and therefore, the aim of the present study was to explore whether other factors impact the survival and development of contralateral breast cancer $(\mathrm{CBC})$ at the early stage.

\section{Materials and methods}

Patients. This study retrospectively collected the clinical and pathological data of a total of 85 early-stage breast cancer patients (pT1aN0M0) who were treated at the Central Hospital of Grenoble University (Grenoble, France) between January 2001 and December 2008. All patients underwent surgery, however, the post-operative treatments varied, including radiotherapy (RT), hormone therapy, chemotherapy and observation. The follow-up time ranged between three and 127 months. Overall, eight patients (9\%) were lost to follow-up. The pre-operative examinations included annual breast cancer screening reports, taking a family history, a physical examination, routine laboratory tests, tumor marker analysis, bilateral mammography or chest radiograph, examination of the sentinel lymph node, abdominal/pelvic contrast-enhanced computed tomography and magnetic resonance imaging. This study was approved by the ethics committee of the Central Hospital of Grenoble University.

Inclusion and exclusion criteria. The criteria used to select the patients were as follows: i) The patient must be diagnosed in the region of Rhone-Alpes and treated at the Central 
Hospital of Grenoble, with no history of breast cancer prior to January 2001. ii) an Eastern Cooperative Oncology Group performance status of 0-2 prior to surgery; iii) patients were included if they presented with other types of systemic disease, including hypertension and diabetes, but excluded if the condition was considered a contraindication of surgery; iv) patients did not present with other primary tumors; v) all tumors were $\leq 5 \mathrm{~mm}$ at the greatest dimension according to the pathological report; and vi) microinvasion of the primary tumor of 1-3 mm in the longest diameter, determined as ductal carcinoma in situ (DCIS) or lobular carcinoma in situ (LCIS), according to the pathological reports, and not as a satellite lesion or metastasis.

Treatments. The treatment strategies predominantly included surgery, RT, hormone therapy, chemotherapy and observation. All patients underwent surgery, including quadrantectomy, mastectomy or lumpectomy. Examination of the lymph nodes included an examination of the sentinel lymph node and dissection of the axillary lymph nodes. In addition, all patients received RT (50 Gy/25 fractions for five weeks), with the exception of patients with microinvasion or without any trace of the tumor bed following biopsy. The patients received 50 Gy of internal mammary chain RT if the tumor was located in the internal quadrant of the breast. The administration of 45 Gy to the supraclavicular area following axillary dissection was insufficient. Either 6-MV photon $\mathrm{X}$ or electrons were used to administer a boost of $10 \mathrm{~Gy}$ to the tumor bed in patients with high-risk factors of relapse, including an age of $<60$ years old, R1 (it has been observed that tumor cells remain in the surgical margin when viewed under the microscope) and high-risk family history ( $\geq 1$ family members have breast cancer). Patients with Her-2(+++) overexpression, according to the ASCO-CAP HER2 Test Guideline Recommendations (12) where Her-2(+++) is defined as uniform intense membrane staining of $>30 \%$ of the invasive tumor cells, were administered six 21 day cycles of a fluorouracil (intravenous, $500 \mathrm{mg} / \mathrm{m}^{2}$, days 1 and 8), epirubicin $\left(75 \mathrm{mg} / \mathrm{m}^{2}\right.$, day 1) and cyclophosphamide $\left(500 \mathrm{mg} / \mathrm{m}^{2}\right.$, day 1$)$ regimen of chemotherapy, which lasted 4.5 months. Hormone therapy with tamoxifen or anti-aromatase inhibitors was offered for hormone receptor-positive patients. Observation was only recommended for the following patients: i) Those at low-risk of recurrence, including those $\geq 60$ years old, those with no relevant family history and a performance state of 0 ; and ii) those refusing any treatment following surgery. The medical characteristics of the patients are presented in Table I.

Follow-up. Every three months, the patients were followed up and obtained results from mammography and biochemistry analyses. In total, $30 \%$ of patients returned to the Central Hospital of Grenoble University, while $61 \%$ visited their family doctors. The period of follow-up was from the date of surgery to the October 15, 2011. Local recurrence or new breast cancer were confirmed by histological examination.

Statistical analysis. Data are presented as the mean \pm standard deviation or as $\mathrm{n}(\%)$. To assess the differences between the groups, Student's t-test was used for continuous variables, and the $\chi^{2}$ test was used for categorical variables. $\mathrm{P}<0.05$ was considered to indicate a statistically significant difference.
Table I. Patient characteristics $(n=85)$.

\begin{tabular}{lr}
\hline Characteristics & $\mathrm{n}$ \\
\hline Age, years & \\
$\leq 55$ & 37 \\
$>55$ & 48 \\
Postmenopausal & \\
Yes & 55 \\
No & 22 \\
Unknown & 8 \\
Family history & \\
1st degree & 12 \\
2nd degree & 24 \\
No & 26 \\
Unknown & 23
\end{tabular}

Surgery type

Lumpectomy

Mastectomy

Qyadrantectomy $\quad 50$

Histology type

ILC 12

IDC $\quad 71$

Others

SBR

Grade I

Grade II

Grade III

Unknown

Microinvasion

High-grade 16

Medium-grade $\quad 15$

Low-grade 3

None $\quad 26$

Unknown 25

Adjuvant treatment

HT

$\mathrm{HT}+\mathrm{RT}-17$

RT

$\mathrm{CT}+\mathrm{RT}$

$\mathrm{CT}+\mathrm{HT}$

Observation

Hormone receptor

$\mathrm{ER}^{+} / \mathrm{PR}^{+}$

$\mathrm{ER}^{-} / \mathrm{PR}^{-}$

$\mathrm{ER}^{+} / \mathrm{PR}^{-}$

$\mathrm{ER}^{-} / \mathrm{PR}^{+}$

Unknown

Boost technique

Yes

No

Her-2(+++)

Yes

No

Unknown

HT, hormonotherapy; RT, radiotherapy; CT, chemotherapy; ILC, invasive lobular carcinoma; IDC, invasive ductal carcinoma; ER, estrogen receptor; PR, progesterone receptor; MBRs, membrane bioreactors; SBR, Scarff-Bloom-Richardson. 
Table II. DFS by variable prognostic factors $(n=85)$.

\begin{tabular}{|c|c|c|c|c|}
\hline \multirow[b]{2}{*}{ Factor } & \multicolumn{4}{|c|}{ DFS, $\%$} \\
\hline & $\mathrm{n}$ & 1-year $(95 \%$ CI) & 3 -year (95\% CI) & 5 -year $(95 \% \mathrm{CI})$ \\
\hline \multicolumn{5}{|l|}{ Age, years } \\
\hline$\leq 55$ & 37 & $97.2(81.8-99.6)$ & 97.2 (81.8-99.6) & $87.0(63.7-95.8)$ \\
\hline$>55$ & 48 & 97.9 (85.8-99.7) & 95.6 (83.5-98.9) & $95.6(83.5-98.9)$ \\
\hline \multicolumn{5}{|l|}{ Postmenopausal } \\
\hline Yes & 55 & $98.2(87.6-99.7)$ & $96.1(85.2-99.0)$ & $92.4(77.0-97.7)$ \\
\hline No & 22 & $95.2(70.7-99.3)$ & $95.2(70.7-99.3)$ & $95.2(70.7-99.3)$ \\
\hline Unknown & 8 & 100.0 & 100.0 & $83.3(27.3-97.5)$ \\
\hline \multicolumn{5}{|l|}{ Family history } \\
\hline 1st degree & 12 & $91.0(50.8-98.7)$ & $91.0(50.8-98.7)$ & $72.7(24.1-93.1)$ \\
\hline 2nd degree & 24 & 100.0 & 95.5 (71.9-99.3) & 95.5 (71.9-99.3) \\
\hline No & 26 & 100.0 & 100.0 & $92.3(56.6-98.9)$ \\
\hline Unknown & 23 & 95.7 (72.9-99.4) & 95.7 (72.9-99.4) & 95.7 (72.9-99.4) \\
\hline \multicolumn{5}{|l|}{ Surgery type } \\
\hline Lumpectomy & 2 & 100.0 & 100.0 & 100.0 \\
\hline Mastectomy & 33 & 96.9 (79.8-99.6) & 96.9 (79.8-99.6) & $92.0(70.8-98.0)$ \\
\hline Quadrantectomy & 50 & $98.0(86.4-99.7)$ & 95.7 (83.8-98.9) & $91.1(72.9-97.3)$ \\
\hline \multicolumn{5}{|l|}{ Histology type } \\
\hline ILC & 12 & 100.0 & 90.9 (50.8-98.7) & $90.9(50.8-98.7)$ \\
\hline IDC & 71 & $97.1(88.9+99.3)$ & $97.1(88.9+99.3)$ & $91.7(79.5+97.0)$ \\
\hline Others & 2 & 100.0 & 100.0 & 100.0 \\
\hline \multicolumn{5}{|l|}{ SBR } \\
\hline I & 37 & $97.2(81.9-99.6)$ & 97.2 (81.9-99.6) & $90(71.9-96.7)$ \\
\hline II & 23 & 100.0 & 94.7 (68.1-99.2) & $94.7(68.1-99.2)$ \\
\hline III & 9 & 88.9 (44.3-98.4) & 88.9 (44.3-98.4) & $88.9(44.3-98.4)$ \\
\hline Unknown & 16 & 100.0 & 100.0 & 100.0 \\
\hline \multicolumn{5}{|l|}{ Microinvasion } \\
\hline High-grade & 16 & 100.0 & 100.0 & 100.0 \\
\hline Medium-grade & 15 & 85.7 (53.9-96.2) & 85.7 (53.9-96.2) & $73.5(35.9-91.1)$ \\
\hline Low-grade & 3 & 100.0 & 100.0 & 0.0 \\
\hline None & 26 & 100.0 & 96.0 (74.8-99.4) & $96(74.8-99.4)$ \\
\hline Unknown & 25 & 100.0 & 100.0 & $92.9(59.1-99.0)$ \\
\hline \multicolumn{5}{|l|}{ Adjuvant treatment } \\
\hline HT & 3 & 100.0 & 100.0 & 100.0 \\
\hline $\mathrm{HT}+\mathrm{RT}$ & 17 & 100.0 & 100.0 & 100.0 \\
\hline RT & 54 & $98.1(87.4-99.7)$ & $96.1(85.3-99.0)$ & $89.7(74.1-96.1)$ \\
\hline $\mathrm{CT}$ & 1 & 100.0 & 100.0 & 100.0 \\
\hline $\mathrm{CT}+\mathrm{HT}$ & 1 & 100.0 & 100.0 & 100.0 \\
\hline Observation & 9 & $88.9(43.3-98.4)$ & 88.9 (43.3-98.4) & $44.4(1.0-86.6)$ \\
\hline \multicolumn{5}{|l|}{ Hormone receptor } \\
\hline $\mathrm{ER}^{+} / \mathrm{PR}^{+}$ & 50 & 97.9 (86.1-99.7) & 97.9 (86.1-99.7) & $89.4(69.3-96.6)$ \\
\hline $\mathrm{ER}^{+} / \mathrm{PR}^{-}$ & 19 & 100.0 & $94.1(65.0-99.2)$ & $94.1(65.0-99.2)$ \\
\hline $\mathrm{ER}^{-} / \mathrm{PR}^{-}$ & 7 & 100.0 & 100.0 & 100.0 \\
\hline $\mathrm{ER} / \mathrm{PR}^{+}$ & 5 & $80.0(20.4-96.9)$ & 80.0 (20.4-96.9) & $80.0(20.4-96.9)$ \\
\hline Unknown & 4 & 100.0 & 100.0 & 100.0 \\
\hline \multicolumn{5}{|l|}{ Boost technique } \\
\hline Yes & 45 & 100.0 & $97.1 \pm 2.9$ & $91 \pm 6.5$ \\
\hline No & 40 & $95.6 \pm 3.1$ & $95.6 \pm 3.1$ & $92 \pm 4.6$ \\
\hline \multicolumn{5}{|l|}{ Her-2(+++) } \\
\hline Yes & 9 & 100.0 & 100.0 & 100.0 \\
\hline No & 39 & $94.9(81.0-98.7)$ & 94.9 (81.0-98.7) & $88.6(65.0-96.7)$ \\
\hline Unknown & 37 & 100.0 & $97.0(80.3-99.6)$ & $93.2(75.4-98.3)$ \\
\hline
\end{tabular}

DFS, disease-free survival; HT, hormone therapy; RT, radiotherapy; CT, chemotherapy; ILC, invasive lobular carcinoma; IDC, invasive ductal carcinoma; ER, estrogen receptor; PR, progesterone receptor; MBRs, membrane bioreactors; SBR, Scarff-Bloom-Richardson; CI, confidence interval. 
Table III. Univariate analysis by multiple potential factors for DFS (log-rank test).

\begin{tabular}{|c|c|c|}
\hline Factor & $\mathrm{n}$ & P-value \\
\hline \multicolumn{3}{|l|}{ Age, years } \\
\hline$\leq 55$ & 37 & \\
\hline$>55$ & 48 & 0.6006 \\
\hline \multicolumn{3}{|l|}{ Postmenopausal } \\
\hline Yes & 55 & \\
\hline No & 22 & \\
\hline Unknown & 8 & 0.8589 \\
\hline \multicolumn{3}{|l|}{ Family history } \\
\hline 1st degree & 12 & \\
\hline 2nd degree & 24 & \\
\hline No & 26 & \\
\hline Unknown & 23 & $0.0352^{\mathrm{a}}$ \\
\hline \multicolumn{3}{|l|}{ Surgery type } \\
\hline Lumpectomy & 2 & \\
\hline Mastectomy & 33 & \\
\hline Quadrantectomy & 50 & 0.7785 \\
\hline \multicolumn{3}{|l|}{ Histology type } \\
\hline ILC & 12 & \\
\hline IDC & 71 & \\
\hline Others & 2 & 0.9317 \\
\hline \multicolumn{3}{|l|}{ SBR } \\
\hline I & 37 & \\
\hline II & 23 & \\
\hline III & 9 & \\
\hline Unknown & 16 & 0.5814 \\
\hline \multicolumn{3}{|l|}{ Microinvasion } \\
\hline High-grade & 16 & \\
\hline Medium-grade & 15 & \\
\hline Low-grade & 3 & \\
\hline None & 26 & \\
\hline Unknown & 25 & $0.0425^{\mathrm{a}}$ \\
\hline \multicolumn{3}{|l|}{ Adjuvant treatment } \\
\hline HT & 3 & \\
\hline $\mathrm{HT}+\mathrm{RT}$ & 17 & \\
\hline RT & 54 & \\
\hline $\mathrm{CT}$ & 1 & \\
\hline $\mathrm{CT}+\mathrm{HT}$ & 1 & \\
\hline Observation & 9 & 0.1916 \\
\hline \multicolumn{3}{|l|}{ Hormone receptor } \\
\hline $\mathrm{ER}^{+} / \mathrm{PR}^{+}$ & 50 & \\
\hline $\mathrm{ER}^{-} / \mathrm{PR}^{-}$ & 7 & \\
\hline $\mathrm{ER}^{+} / \mathrm{PR}^{-}$ & 19 & \\
\hline $\mathrm{ER}^{-} / \mathrm{PR}^{+}$ & 5 & \\
\hline Unknown & 4 & 0.6019 \\
\hline \multicolumn{3}{|l|}{ Boost technique } \\
\hline Yes & 45 & \\
\hline No & 40 & 0.6546 \\
\hline \multicolumn{3}{|l|}{ Her-2(+++) } \\
\hline Yes & 9 & \\
\hline No & 39 & \\
\hline Unknown & 37 & 0.3722 \\
\hline
\end{tabular}

${ }^{\mathrm{a}} \mathrm{P}<0.05$. DFS, disease-free survival; HT, hormone therapy; RT, radiotherapy; CT, chemotherapy; ILC, invasive lobular carcinoma; IDC, invasive ductal carcinoma; ER, estrogen receptor; PR, progesterone receptor; MBRs, membrane bioreactors; SBR, Scarff-Bloom-Richardson.

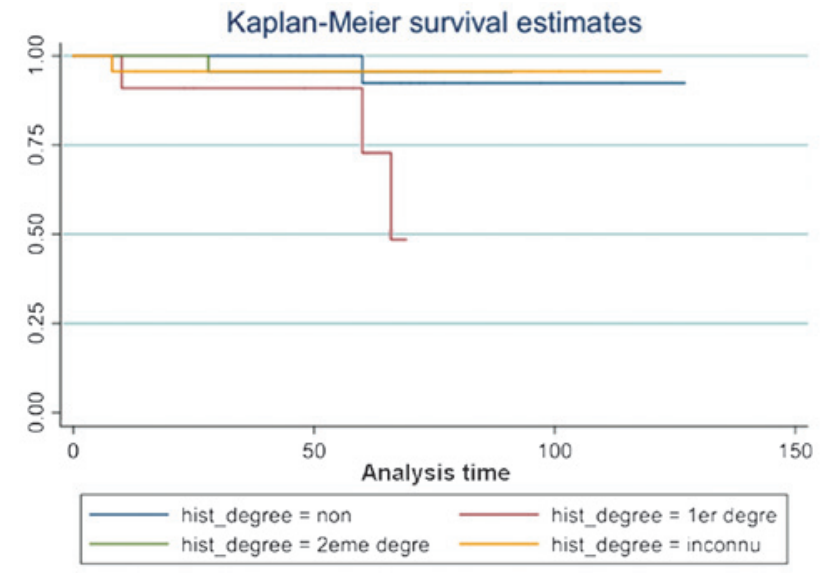

Figure 1. Disease-free survival by family history (Kaplan-Meier). The Kaplan-Meier estimates revealed that the first degree of family history, which describes the family member with breast cancer (daughter, mother or sibling), is the most important for the occurrence of new contralateral breast cancer. Whilst the second degree of family history (aunt or niece), without family history or other status, lessens the revolution. Hist_degree, degree of family history; non, no family history; 1ere degree, first degree family history; 2eme degree, second degree family history; inconnu, unknown.

Statistical analysis was performed using STATA software (version 10; Stata Corporation, College Station, TX, USA). Disease-free survival (DFS) time was estimated using Kaplan-Meier analysis. The log-rank test was used to evaluate the effects of different individual variable factors on the relapse-free survival time. The overall survival (OS) time was defined as the elapsed interval between the date of the initial surgery to mortality, loss to follow-up or October 15, 2011. The DFS time was defined as the time from the date of surgery to the date of local recurrence or new CBC.

\section{Results}

Treatment. In total, 85 patients underwent surgery and 72 patients received RT, of which, 40 were administered boost irradiation. Furthermore, 21 patients received hormone therapy and two patients received chemotherapy, which was followed by an additional herceptin treatment for one year in one patient. Herceptin dosages were dependent on the weight of the patient: herceptin dose for the first cycle $(\mathrm{mg} / \mathrm{kg})=6 \mathrm{mg}$ x weight of patient $(\mathrm{kg})$; herceptin dosage for the second to final cycle $(\mathrm{mg} / \mathrm{kg})=4 \mathrm{mg} \mathrm{x}$ weight of the patient $(\mathrm{kg})$, each cycle lasts for 21 days and the overall treatment lasts for a year. Seven patients underwent observation only. No local recurrence or mortalities were observed during the follow-up period, however, 11 secondary cancers were identified in 10 patients. This consisted of five cases of secondary CBC and one each of thyroid, bladder, tongue and colon cancer. One patient was identified with cervical and breast cancer on the contralateral side.

OS and DFS analysis. A complete follow-up was achieved in $91 \%(\mathrm{n}=77)$ of patients, while $9 \%(\mathrm{n}=8)$ were lost to follow-up. The follow-up period varied between three and 127 months. The median follow-up period was 60 months. No mortalities occurred during the study period. The corresponding rates of DFS by variable prognostic factors are shown in Table II. 
Table IV. Characteristics of patients with new contralateral breast cancer.

\begin{tabular}{|c|c|c|c|c|c|c|}
\hline Patients & 1 & 2 & 3 & 4 & 5 & 6 \\
\hline Age, years & 47 & 74 & 50 & 53 & 52 & 50 \\
\hline Family history, degree & $1 \mathrm{st}$ & 2nd & $1 \mathrm{st}$ & No & No & $1 \mathrm{st}$ \\
\hline Interval of new tumor, years ${ }^{a}$ & 1 & 2 & 5 & 5 & 1 & 5 \\
\hline Menopausal & No & Yes & Yes & Yes & Yes & Yes \\
\hline $\mathrm{ER} / \mathrm{PR}$ & $+/-$ & $+/+$ & $+/+$ & $+/+$ & $+/+$ & $+/+$ \\
\hline Primary histology & IDC & ILC & ILC & IDC & IDC & IDC \\
\hline Primary histology grade & III & II & I & I & I & I \\
\hline Contralateral cancer histology & IDC & ILC & ILC & ILC & IDC & ILC \\
\hline Size of the second tumor, $\mathrm{mm}$ & Unknown & Unknown & 26 & 9 & 7 & 26 \\
\hline Initial surgery & MT & QT & QT & QT & QT & MT \\
\hline Initial RT & No & Yes & Yes & Yes & Yes & Yes \\
\hline Initial HT & No & No & No & No & No & No \\
\hline Necrosis/LVI & No & No & No & No & No & No \\
\hline Microinvasion, grade & Medium & No & Low & Medium & Medium & Unknown \\
\hline First margin of surgery & $(-)$ & $(-)$ & $(-)$ & $(-)$ & $(-)$ & $(-)$ \\
\hline
\end{tabular}

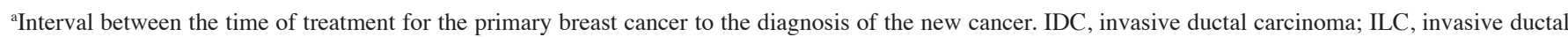
carcinoma; QT, quadrantectomy; MT, mastectomy; LVI, lymphovascular emboli or invasion; ER, estrogen receptor; PR, progesterone receptor; HT, hormonotherapy; RT, radiotherapy.

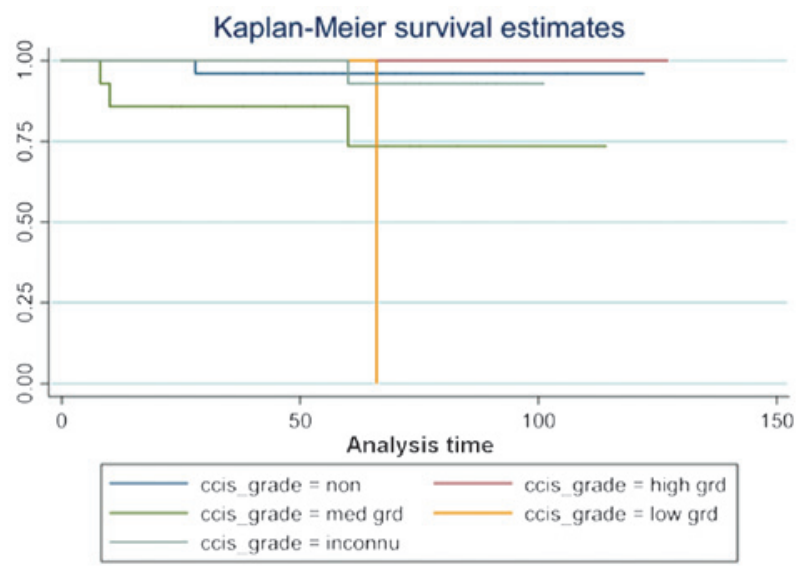

Figure 2. Disease-free survival by satellite lesions presented as ccis associate (Kaplan-Meier). The Kaplan-Meier survival estimates revealed that the lowest degree was considered to be the most important reason for a new occurrence. Among the patients who were detected to have low-grade ductal breast satellite lesions, only one was administered hormone therapy. ccis_grade; grade of microinvasion; non, no micorinvasion; inconnu, unknown.

Prognostic factors for DFS (univariate analysis). As no mortalities were observed in this study, the appearance of CBC was regarded as the evolution of primary breast cancer. The cumulative recurrence for DFS was univariately affected by the known parameters of family history and microinvasion (summarized in Table III and Figs. 1 and 2).

Patients with secondary $C B C$. In this study, six patients were identified with a secondary primary $\mathrm{CBC}$. The patient characteristics are presented in Table IV. Only one patient was $>55$ years old and four had a relevant family history, with three being due to first degree relatives. The rate of CBC was 2.35, 3.53 and $7.06 \%$ at one, two and five years, respectively. Of the six females, five were menopausal, four were identified with invasive ductal carcinoma at the first diagnosis, two with invasive lobular carcinoma, five with low-grade tumors (I+II) and only one with high-grade tumors (III) according to the Bloom-Richardson grading system. By contrast, the histology of the contralateral tumor was reversed; four patients exhibited ILC, while two exhibited IDC. All of these patients received RT, however, none received hormone therapy due to a number of personal reasons. In addition, no necrosis or LVI was identified.

\section{Discussion}

As all patients in the present study were diagnosed with early-stage breast cancer, the study aimed to understand why the rates of $\mathrm{CBC}$ remained so high.

$\mathrm{CBC}$ is considered to be the most common type of secondary cancer for those whose primary cancers are located in the breast, accounting for almost half of all secondary tumors (10). Therefore, the analysis of $\mathrm{CBC}$ is becoming an important public issue. The overall incidence rates of $\mathrm{CBC}$ vary between 4 and 8 per 1,000 individuals per year, with different stages and treatment strategies (11). With regard to the incidence of secondary CBC of early-stage breast cancer, Gao et al (13) observed that the rates of CBC were 2.9, $6.1,9.1$ and $12 \%$ at five, 10,15 and 20 years, respectively. Comparatively, the incidences of $2.35,3.53$ and $7.06 \%$ at one, two and five years that were identified in the current study were marginally lower.

Among the CBC patients in the present study, five out of six were $<55$ years old. Although the study did not report that age impacts the rates of $\mathrm{CBC}$, a number of studies have revealed that females of a young age suffer a greater risk of secondary primary breast cancer. Broët et al (14) identified that patients $<55$ years old [relative risk (RR), 1.40; 95\% confidence interval (CI), 1.10-1.78] were associated with an 
increased risk of CBC. However, another study considered an age of $\leq 45$ years to be a risk factor (15). By contrast, compared with the ages of between 45 and 55 years, Gao et al (13) found an age of $>55$ years to be a risk factor.

In the present study, family history was a key potential risk factor of $\mathrm{CBC}$; this has been confirmed by a number of studies. Reiner et al (16) considered females of <45 years old with first degree relatives to be at the highest risk (RR, 2.5; 95\% CI, 1.1-5.3). A study by Yadav et al (17) also showed that females with a family history had the highest incidence rates of CBC (15.3\%; RR, 1.6; 95\% CI, 1.12-1.27) at 20 years old. Additionally Lizarraga et al (18) found that having multiple first and second degree relatives appeared to increase the risk of CBC by two- or three-fold.

The impact of microinvasion on the rate of $\mathrm{CBC}$ remains controversial, and has been investigated by few studies (19). It is not easy to determine whether microinvasion is a risk factor for CBC or metastasis. However, in this study, the statistical analyses revealed that microinvasion does impact the rates of CBC. A study by Claus et al (20) demonstrated that patients whose primary tumor was diagnosed as LCIS were 2.6 times (95\% CI, 2.0-3.4\%) more likely to develop CBC within the first six months of the initial primary tumor compared with females with DCIS. If the period of follow-up can be extended or more early-stage breast cancer patients are excluded, the potential effect of microinvasion may be observed.

As shown in Table IV, none of the CBC patients received hormone therapy, however, all the patients exhibited indicators of suitability for hormone therapy according to their positive status of ER/PR, which markedly increases the incidence of $\mathrm{CBC}$. Tamoxifen, as a representative of hormone therapy, is well known to reduce the risk of CBC $(21,22)$. Furthermore, in the latest large multiple center study (23), 1,583 patients with BRCA1 mutations and 881 with BRCA2 mutations, 383 (24\%) and $454(52 \%)$ of patients were administered tamoxifen, respectively, following the initial breast cancer diagnosis. This cohort study revealed that the use of tamoxifen may reduce the risk of $\mathrm{CBC}$ for BRCA1 and BRCA2 mutation carriers. However, a study among elderly patients ( $\geq 65$ years old) who were classified as T1N0M0 and treated with breast-conserving surgery and RT showed no significant differences in the 10-year survival of CBC patients or OS between the tamoxifen and non-tamoxifen cohorts (24).

The serine protease urokinase-type plasminogen activator (UPA) and its inhibitor, PAI-1, are considered to be independent, statistically prognostic factors in primary breast cancer. The NNCB-3 trial (23) confirmed the highest level of evidence for the clinical utility of uPA and PAI-1. Furthermore, uPA and PAI-1 also serve as predictive factors of response to adjuvant therapy and the early relapse of breast cancer. At present, examination of UPA/PAI-1 has been essential in the pathological surgical studies of breast cancer in France (25-30), and may be investigated in our future retrospective studies.

In the present study, five other secondary primary cancers were identified, including thyroid, bladder, tongue, colon and cervical cancer. It is likely that multiple factors, including genetic effects, endogenous hormones, pollution, environmental exposure, age and the initial treatments for primary breast cancer, resulted in variations between the standardized incidence ratios in cancer of the digestive system, lungs, uterus, ovaries, kidneys and bladder, soft tissue sarcoma, melanoma and certain types of hematological malignancy $(31,32)$.

In the current study, family history and microinvasion were poor prognostic factors. The most likely reason for this result was insufficient systemic treatment, particularly from hormone therapy. At present, although a consensus has not been reached on the use of adjuvant treatment for early-stage breast cancer, a large quantity of observational and follow-up examinations are being conducted by family doctors, and regularly communication between family doctors and oncologists should be encouraged and regarded as a routine procedure. Oncologists or family doctors should persuade the patients who exhibit indicators of suitability for hormone therapy (positive ER/PR status) to continue the treatment. Furthermore, an increased period of follow-up must be implemented and other significant biomarkers investigated to continue this study further.

\section{References}

1. Balu-Maestro C, Chapellier C, Souci J, Caramella T and Marcotte-Blonch C: Breast cancer screening imaging: what do we do. J Gynecol Obstet Biol Reprod (Paris) 39: 3-10, 2010 (In French).

2. French Institute for Public Health Surveillance; National Cancer Institute France: Projection of the incidence and mortality of cancer in France in 2011. Technical report. French Institute for Public Health Surveillance, Saint-Maurice, p78, 2011.

3. Dinshaw KA, Budrukkar AN, Chinoy RF, Sarin R, Badwe R, Hawaldar R and Shrivastava SK: Profile of prognostic factors in 1022 Indian women with early-stage breast cancer treated with breast-conserving therapy. Int J Radiat Oncol Biol Phys 63: 1132-1141, 2005.

4. Sánchez-Muñoz A, Ribelles $N$ and Alba E: Optimal adjuvant hormonal therapy in postmenopausal women with hormone-receptor-positive early breast cancer: have we answered the question? Clin Transl Oncol 12: 614-620, 2010.

5. Mouridsen HT and Robert NJ: The role of aromatase inhibitors as adjuvant therapy for early breast cancer in postmenopausal women. Eur J Cancer 41: 1678-1689, 2005.

6. Grau JJ,Zanon G, Caso C, Gonzalez X, Rodriguez A, Caballero M and Biete A: Prognosis in women with breast cancer and private extra insurance coverage. Ann Surg Oncol 20: 2822-2827, 2013.

7. Mereno-Aspitia A, Hillman DW, Dyar SH, Tenner KS, Gralow J, Kaufman PA, et al: Soluble human epidermal growth factor receptor 2 (HER2) levels in patients with HER2-positive breast cacner receiving chemotherapy with or without trastuzumab: results from North Central Cancer Treatment Group adjuvant trail N9831. Cancer 119: 2675-2682, 2013.

8. Swenson KK, Decher L, Haselow R, Farrell JB and Sperduto PW: Prognostic factors after conservative surgery and radiation therapy for early stage breast cancer. Am J Clin Oncol 21: 111-116, 1998.

9. Cianfrocca M and Goldstein LJ: Prognostic and predictive factors in early-stage breast cancer. Oncologist 9: 606-616, 2004.

10. Harvey EB and Brinton LA: Second cancer following cancer of the breast in Connecticut, 1935-82. Natl Cancer Inst Monogr 68: 99-112, 1985

11. Chen Y, Thompson W, Semenciw R and Mao Y: Epidemiology of contralateral breast cancer. Cancer Epidemio Biomakers Prev 8: 855-861, 1999.

12. Wolff AC, Hammond ME, Hicks DG, et al: Recommendations for human epidermal growth factor receptor 2 testing in breast cancer: American Society of Clinical Oncology/College of American Pathologists clinical practice guideline update. J Clin Oncol 31: 3997-4013, 2013.

13. Gao X, Fisher SG and Emami B: Risk of second primary cancer in the contralateral breast in women treated for early-stage breast cancer: a population-based study. Int J Radiat Oncol Biol Phys 56: 1038-1045, 2003.

14. Broët P, de la Rochefordière A, Scholl SM, Fourquet A, Mosseri V, Durand JC, et al: Contralateral breast cancer: annual incidence and risk parameters. J Clin Oncol 13: 1578-1583, 1995. 
15. Mariani L, Coradini D, Biganzoli E, Boracchi P, Marubini E, Pilotti S, et al: Prognostic factors for metachronous contralateral breast cancer: a comparison of the linear Cox regression model and its artificial neural network extension. Breast Cancer Res Treat 44: 167-178, 1997.

16. Reiner AS, John EM, Brooks JD, Lynch CF, Bernstein L, Mellemkjær L, et al: Risk of asynchronous contralateral breast cancer in noncarriers of BRCA1 and BRCA2 mutations with a family history of breast cancer: a report from the Women's Environmental Cancer and Radiation Epidemiology Study. J Clin Oncol 31: 433-439, 2013

17. Yadav BS, Sharma SC, Patel FD, Ghoshal S and Kapoor RK: Second primary in the contralateral breast after treatment of breast cancer. Radiother Oncol 86: 171-176, 2008.

18. Lizarraga IM, Sugg SL, Weigel RJ and Scott-Conner CE: Review of risk factors for the development of contralateral breast cancer. Am J Surg 206: 704-708, 2013.

19. Sutherland CM and Mather FJ: Long-term survival and prognostic factors in patients with regional breast cancer (skin, muscle, and/or chest wall attachment). Cancer 55: 1389-1397, 1985.

20. Claus EB, Stowe M, Carter D and Holford T: The risk of a contralateral breast cancer among women diagnosed with ductal and lobular breast carcinoma in situ: data from the Connecticut Tumor Registry. Breast 12: 451-456, 2003.

21. Dalberg K, Johansson H, Johansson U and Rutqvist LE: A randomized trial of long term adjuvant tamoxifen plus postoperative radiation therapy versus radiation therapy alone for patients with early stage breast carcinoma treated with breast-conserving surgery. Stockholm Breast Cancer Study Group. Camcer 82: 2204-2211, 1998.

22. Clarke MJ: WITHDRAWN: Tamoxifen for early breast cancer. Cochrane Database Syst Rev 8: CD000486, 2008.

23. Phillips KA, Milne RL, Rookus MA, Daly MB, Antoniou AC, Peock S, et al: Tamoxifen and risk of contralateral breast cancer for BRCA1 and BRCA2 mutation carriers. J Clin Oncol 31: 3091-3099, 2013.

24. Khan AJ, Parikh RR, Neboori HJ, Goyal S, Haffty BG and Moran MS: The relative benefits of tamoxifen in older women with T1 early-stage breast cancertreated with breast-conserving surgery and radiation therapy. Breast J 19: 490-495, 2013.
25. Annecke K, Schmitt M, Euler U, Zerm M,Paepke D, Paepke S, et al: uPA and PAI-1 in breast cancer: review of their clinical utility and current validation in the prospective NNBC-3 trial. Adv Clin Chem 45:31-45, 2008.

26. Lamy PJ, Romieu G and Jacot W: UPA/PAI-1: a tool for breast cancer treatment individualization. Biology, clinical implications and quantification assays. Bull Cancer 97: 341-348, 2010 (In French).

27. Eljuga D, Razumovic JJ, Bulic K, Petrovecki M, Draca N and Bulic SO: Prognostic importance of PAI-1 in node negative breast cancer patients - results after 10 years of follow up. Pathol Res Pract 207: 290-294, 2011.

28. Schmitt M, Mengele K, Napieralski R, Magdolen V, Reuning U, Gkazepis A, et al: Clinical utility of level-of-evidence-1 disease forecast cancer biomakers uPA and its inhibitor PAI-1. Expert Rev Mol Diagn 10: 1051-1067, 2010.

29. Kantelhardt EJ, Vetter M, Schmidt M, Veyret C, Augustin D, Hanf V, et al: Prospective evaluation of prognostic factors uPA/PAI-1 in node-negative breast cancer: phase III NNBC3-Europe trial (AGO, GBG, EORTC-PBG) comparing 6xFEC versus $3 x F E C / 3 x$ Docetaxel. BMC Cancer 11: 140 , 2011.

30. Dazzi C, Cariello A, Maioli P, Magi S, Rosti G, Giovanis P, et al: A high cytosol value of urokinase-type plasminogen activator (UPA) may be predictive of early relapse in primary breast cancer. Cancer Invest 21: 208-216, 2003.

31. Rubino C, de Vathaire F, Diallo I, Shamsaldin A and Lê MG: Increased risk of second cancers following breast cancer: role of the initial treatment. Breast Cancer Res Treat 61: 183-195, 2000.

32. Schaapveld M, Visser O, Louwman MJ, de Vries EG, Willemse PH, Otter R, et al: Risk of new primary nonbreast cancers after breast cancer treatment: a Dutch population-based study. J Clin Oncol 26: 1239-1246, 2008. 